\section{Are Financial Jobs Morally Unjustifiable?}

\section{Janusz KonieCZny}

The Mathematical Intelligencer encourages comments

about the material in this issue. Letters to the editor

should be sent to either of the editors-in-chief, Chandler

Davis or Marjorie Senechal. n the Summer 2011 Viewpoint, Jonathan Korman passes a moral judgment on the mathematicians (and others) who work for banks (Korman, J., "Finance and Mathematics: A Lack of Debate", The Mathematical Intelligencer 33 (2011) no. 2, 4-6). "These jobs are morally unjustifiable," he declares. The reason is that in J. Korman's opinion (which he apparently considers to be a self-evident truth) the banks constitute "a destructive financial industry," and they are "known for looting the public." Many of the mathematicians working for banks "feel no moral issue," J. Korman divines, just like Adolf Eichmann, who, while sending millions of Jews to gas chambers, "was incapable of thinking about the moral consequences of his actions." There is a mitigating factor, though. Mathematics departments are "complicit in setting the trap" and they are "handing over many students to the banks." So, J. Korman adds, "it is not fair to put the burden only on individuals." After all, he clarifies, we hold Eichmann "responsible for his crimes, but the system in which he operated had its role."

Controversy is welcome in Viewpoint, but the editors may exercise their right not to print some views. The comparison of a large group of mathematicians (and others) to Nazi murderers may well be one of many things that is not worth printing.

Department of Mathematics

University of Mary Washington

Fredericksburg, VA 22401

USA

e-mail: jkoniecz@umw.edu

Editors' Note: As we read Dr. Korman's Viewpoint article (vol. 33, no. 2, 4-6), he compares work in finance to Nazi atrocities not in the nature of the deeds, which are plainly dissimilar, but in the way the moral issues are left unexamined. Thus his subtitle: "A Lack of Debate". 